\title{
Surgical excision of perineal nodular induration: A cyclist's third testicle
}

\author{
Mohannad A. Awad, MD 1,2, Gregory P. Murphy, MD'; Thomas W. Gaither, $M D^{\prime}$; E. Charles Osterberg, $M D^{3}$; \\ Thomas A. Sanford, $M D^{1}$; Andrew E. Horvai, MD'; Benjamin N. Breyer ${ }^{1,5}$
}

'Department of Urology, University of California-San Francisco, San Francisco, CA, United States, ${ }^{2}$ Department of Surgery, King Abdulaziz University, Rabigh, Saudi Arabia; ${ }^{3}$ Department of Surgery, University of Texas, Dell Medical School, Austin, TX, United States; ${ }^{4}$ Department of Pathology, University of California-San Francisco, San Francisco, CA, United States; ${ }^{5}$ Department of Biostatistics and Epidemiology, University of California-San Francisco, San Francisco, CA, United States

Cite as: Can Urol Assoc J 2017;11 (5):E244-7. http://dx.doi.org/10.5489/cuaj.4169

Published online May 9, 2017

\section{Abstract}

Perineal nodular induration ( $\mathrm{PNI})$, or biker's nodule, is a rare, bothersome, pseudotumour. Herein, we describe the surgical technique used to treat a healthy cyclist who developed an enlarging PNI for five years that grew into a perineal mass. The mass prevented him from cycling due to worsening discomfort and heaviness. The $\mathrm{PNI}$-associated mass was successfully removed by wide surgical excision and a local advancement flap. Subsequently, the patient resumed cycling. Histopathology report demonstrated a benign lesion with abundant ropy collagen with native smooth muscle, vessels, and rare fibroblast-like spindle cells. With the increasing popularity of cycling, PNI may become more common, and health providers should be aware of this rare entity and how it can be safely removed.

\section{Introduction}

Bicycle riding is one of the most popular methods for transportation, exercise, and leisure. According to U.S. Bicycling Participation Benchmarking 2015 report, 34\% or 103.7 million Americans (ages three and older) rode a bicycle at least once in the past year, with $14 \%$ of this population reporting frequent riding more than 104 times/year. ${ }^{1}$ The health benefits of bicycling as an aerobic exercise are wellknown. ${ }^{2-4}$ Endurance cycling may cause injuries affecting the genitourinary system. ${ }^{5}$ Perineal nodular induration (PNI) also known as biker's nodule, cyclist's nodule, ischiatic hygroma, third testicle, or an accessory testicle is a benign pseudotumour that presents most commonly in avid male cyclists with repetitive perineal microtrauma. ${ }^{6}$ It usually develops posterior to the scrotum in the soft tissue of the perineum, as two masses on both sides of the median raphe, or as a single mass located midline, or lateralized over the ischial tuberosity. ${ }^{6}$ Herein, we report our surgical technique for PNI treatment and the histopathological characteristics of PNI.

\section{History}

A 48-year-old healthy male who is an avid cyclist presented with a progressive inferior perineal and scrotal swelling for five years. He had been actively cycling for 20 years, riding an average of 100 miles/week. When he presented to our clinic, he complained of redundant scrotal and perineal skin. He reported a history of saddle sores that resolved in the past. On physical examination, there was a large, mobile, non-tender, and soft mound of perineal tissue that was posterior to the scrotum with redundant tissue, covered by normal skin (Fig. 1). Ultrasound of the scrotum demonstrated redundant soft tissue in the perineum inferior to the raphe. The bulge restricted the patient's daily activity and he opted for surgical excision.

\section{Surgical technique}

The patient was placed in a lithotomy position. An elliptical incision was made from the apex, near the scrotum, down to $2 \mathrm{~cm}$ above the anus. The dissection was superior to the bulbospongiosus muscle. After complete mobilization, the mass was transected and sent to pathology. It measured approximately $14 \times 5 \mathrm{~cm}$ (Fig. 2). In order to close the incision in a tension-free manner, lateral flaps were raised that were approximately $15 \times 3 \mathrm{~cm}$. The subcutaneous layers were closed using interrupted 2-0 vicryl for the deep and superificial layers. In total, there were four layers of closure. The patient tolerated the procedure well and was discharged in the same day in a good condition.

\section{Pathology}

Grossly, the specimen consisted of a $14 \times 5.5 \mathrm{~cm} \times 2 \mathrm{~cm}$ thick fragment of hair-bearing skin and subcutaneous tissue 


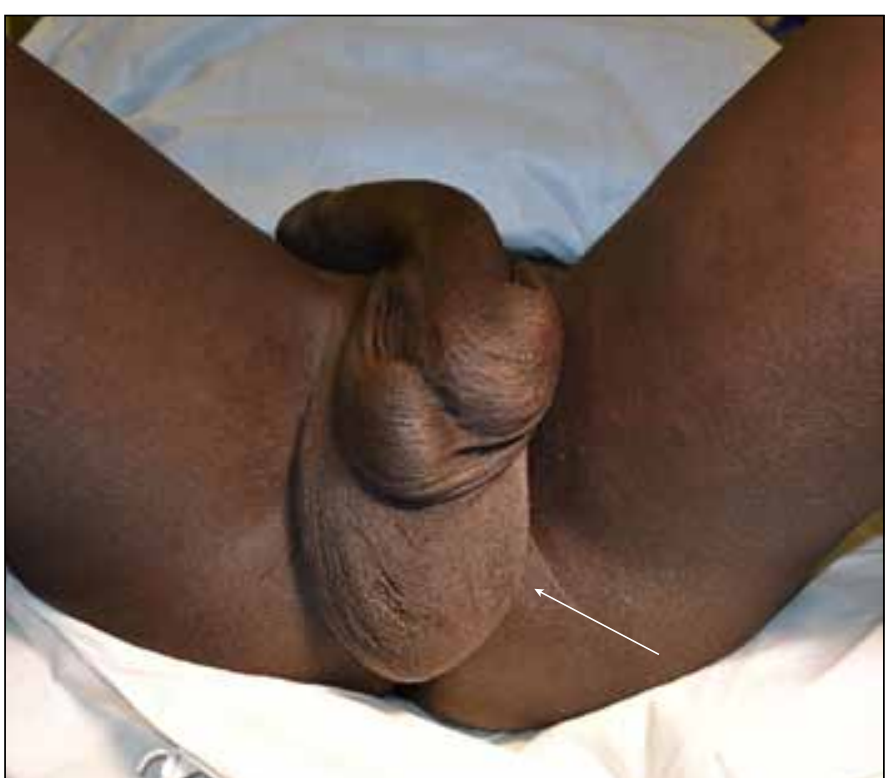

Fig. 1. Large, perineal fat posterior to the scrotum with redundant tissue resembling an accessory testicle (arrow).

with a homogeneous, fibrotic cut surface. The epidermis and dermis were unremarkable microscopically (not shown). The deeper soft tissues showed abundant ropy collagen bundles mixed with native smooth muscle, vessels, and rare fibroblast-like spindle cells. There was no atypia, necrosis, or mitotic activity (Fig. 3).

\section{Followup}

The patient began cycling roughly two months after the operation with mild discomfort that improved over time. He denied any sexual or urinary side effects. Fig. 4 shows

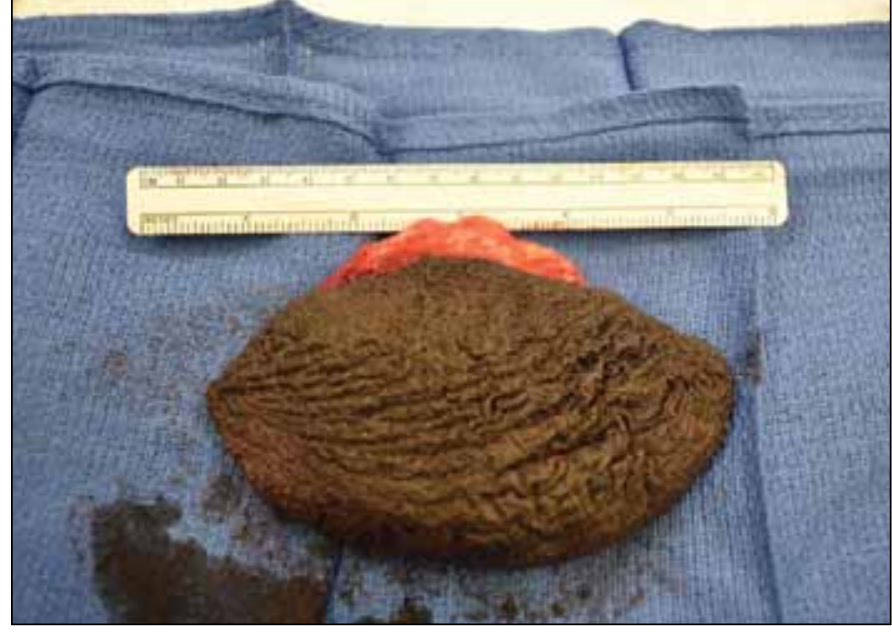

Fig. 2. Excised mass measuring approximately $14 \times 5 \mathrm{~cm}$.

the patient's perineum and scrotum in followup, with no signs of residual mass at two months' followup.

\section{Discussion}

Although the pathogenesis of $\mathrm{PNI}$ is unknown, it may be related to the repetitive compression and friction of the perineal fascia between the bike's saddle and ischial tuberosities. ${ }^{7}$ Beyond cyclists, this complication has been documented in a patient who was an equestrian and another who tested lawn mowers. ${ }^{8,9}$ It is more commonly seen in males, but recently, five female cases have been reported. ${ }^{9,10}$ Its latency period varies from a few weeks to one year. Although the nodule in our case was mobile, most reports state that it is fixed to the soft tissue or ischial tuberosity, has a fibrous to elastic consistency, and is covered by normal skin. ${ }^{6,7,11}$

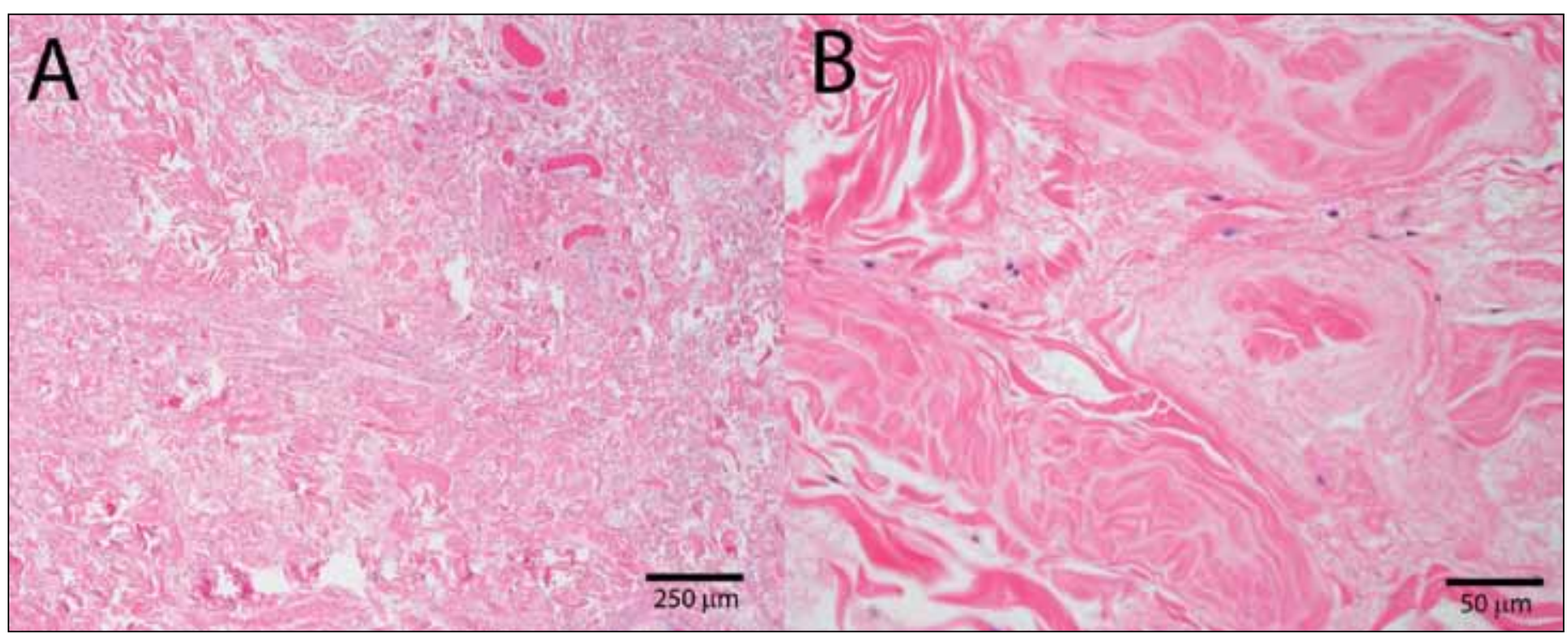

Fig. 3. (A) Microscopically, the excision specimen demonstrated abundant ropy collagen with rare, bland fibroblast-like spindle cells mixed with native smooth muscle and small vessels; $(\boldsymbol{B})$ at higher magnification, some of the collagen bundles showed a hyaline, keloidal quality. 
Awad et al.

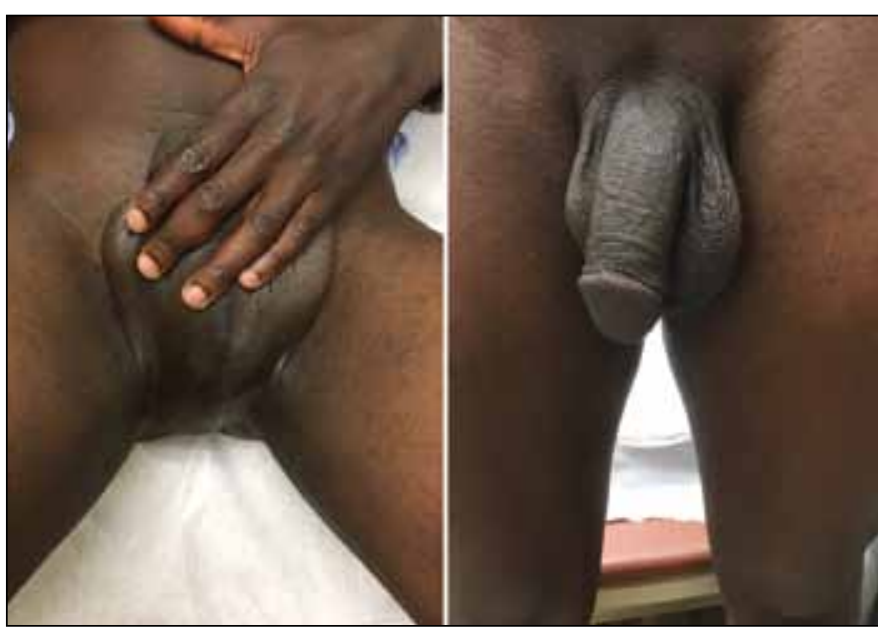

Fig. 4. Patient perineum and scrotum at two months' followup showing no signs of residual mass.

The histopathological appearance of PNI varies. It is often characterized by a central pseudocystic space surrounded by fibrous tissue containing fibroblast spindle cells and clusters of small-sized vessels., ${ }^{711,12}$ The central pseudocystic space somewhat resembles that seen in ischemic fasciitis, which occur in elderly patients over the bony prominences who are often, though not always, immobilized. ${ }^{13-15}$ Other possible differential diagnoses are listed in Table 1.

In most cases, history and physical examination can diagnose PNI. Imaging modalities, such as ultrasound and magnetic resonance imaging, may be needed in some cases. Final diagnosis is made by histopathological examination. Primary treatment options include adjustment of cyclist position to change the distribution of weight on the saddle, as well as limiting the source of friction, which includes using adequate saddle/perineal lubricant and proper fitting cycling clothing. Patients can be counselled that there are no reports of spontaneous regression, but it is possible to limit progression and discomfort. Second, some authors reported that intralesional corticosteroids or hyalurodinase injection may offer some relief. These injections are only preferable for small nodules and may cause subcutaneous atrophy. ${ }^{22,23}$ Both of the previous treatment options were not suitable for our patient, as the mass was quite large and bothersome. Finally, surgical excision of the mass is the most often used treatment with superior results. ${ }^{6}$ The technique to remove this mass could vary depending on the exact size and location. With smaller masses, the need to raise local skin flaps as in our case, may not be necessary. For larger masses, if skin flaps cannot be mobilized well enough, a split-thickness skin graft could also be applied to any areas not able to be closed in a tension-free manner.

\section{Conclusion}

$\mathrm{PNI}$ is a poorly recognized, rare, bothersome benign pseudotumour that mostly appears in professional and avid cyclists. Diagnosis is made by clinical history and examination. Surgical excision is the treatment of choice. With the increasing popularity of cycling, PNI may become more common, and healthcare providers should be aware of this entity and how it can be safely removed.

Competing interests: This research was funded by the Bicycle React Grant. The authors report no competing personal or financial interests.

This paper has been peer-reviewed.

\section{References}

1. PeopleforBikes. U.S. Bicycling Participation Benchmarking Study Report 2015. July 20, 2016]; Available at http://b.3cdn.net/bikes/7b69b6010056525bce_iim6vs5ql.pdf. Accessed March 24, 2017.

\section{Table 1. Differential diagnoses for perineal nodular induration}

\section{Differential diagnosis}

Ischemic fasciitis ${ }^{13-15}$

Cellular angofibrom*16

Angiomyofibroblastoma-like tumour of the male genital tract*17

Mammary type fibroblastoma*18

Massive localized lymphedema ${ }^{19}$

Prepuberal vulvar formation ${ }^{20}$

Childhood asymmetric labium majus enlargement ${ }^{21}$

\section{Histolopathological features}

Outer fringe of mitotically active fibroblasts and occasional ganglion-like cells and small vessels surrounding a central zone of necrobiosis

Uniformly moderately cellular with plump, bland spindle cells, hyalinized round, thick and walled vessels may contain adipose tissue

Alternating hypercellular and hypocellular areas with clusters of rounded, epithelioid cells around numerous small vessels

Well-circumscribed, more cellular, and lacks a central zone pattern. Bundles of thick, ropy collagen with inconspicuous vessels may contain adipose tissue

Edematous stroma, dilated vascular channels, and mature adipose tissue separated by fibrous septa

Poorly marginated, hypocellular tumours, formed by bland of spindle-shaped cells in a collagenous to edematous or myxoid stroma

Rare to moderate cellular interconnected fibrous bands, encircled lobules of fat, vessels, and nerves

*These three entities are closely related and may represent variants of a single entity. 
2. Powell KE, Thompson PD, Caspersen CJ, et al., Physical activity and the incidence of coronary heart disease Annu Rev Public Health 1987;8:253-87. https://doi.org/10.1146/annurev.pu.08.050187.001345

3. Williams PT, Reduction in incident stroke risk with vigorous physical activity. Evidence from 7.7-year followup of the National Runners' Health Study. Stroke 2009;40:1921-3. https://doi.org/10.1161/ STROKEAHA. 108.535427

4. Williams PT. Vigorous exercise, fitness, and incident hypertension, high cholesterol, and diabetes. Med Sci Sports Exerc 2008;4:998. https://doi.org/10.1249/MSS.0b013e31816722a9

5. Leibovitch I, Mor Y. The vicious cycling: Bicycling related urogenital disorders. Eur Urol 2005; 47:277-87. https://doi.org/10.1016/i.eururo.2004.10.024

6. Creff A, Melki F, Ceccaldi M, et al. L'hygroma ischiatique ou "troisième testicule du stayer". Réflexion à propos de l'étiopathogénie, du traitement et de la prévention. Med Sport 1985;59:296-300.

7. de Saint Aubain Somerhausen N, Geurde B, Couvreur Y. Perineal nodular induration: The 'third testicle of the cyclist', an under-recognized pseudotumour. Histopathology 2003;42:615-6. https://doi.org/10.1046/i.1365-2559.2003.01592.x

8. Pedio G, Zoebeli L, Rust B. A rare case of" occupational disease." Acta Cytol 1986;30:453-4.

9. Devers $\mathrm{KG}$, Heckman $S R$, Muller $C$, et al. Perineal nodular induration: a trauma-induced mass in a female equestrian. Int J Gynecol Pathol 2010;29:398-401. https://doi.org/10.1097/PGP.0b013e3181cel341

10. McCluggage WG, Smith JH. Reactive fibroblastic and myofibroblastic proliferation of the vulva (cyclist's nodule): A hitherto poorly described vulval lesion occurring in cyclists. Am I Surg Pathol 201 1;35:110-4. https://doi.org/10.1097/PAS.0b013e3181ffd8ab

11. Vuong P, Camuzard P, Schoonaert M. Perineal nodular indurations ("accessory testicles") in cyclists. Fineneedle aspiration cytologic and pathologic findings in two cases. Acta Cytol 1987;32:86-90.

12. Khedaoui R, Martín-Fragueiro LM, Tardío JC. Perineal nodular induration ("biker's nodule"): Report of two cases with fine-needle aspiration cytology and immunohistochemical study. Int I Surg Pathol 2014;22:715. https://doi.org/10.1177/1066896912465008

13. Montgomery EA, Meis JM, Mitchell MS, et al. Atypical decubital fibroplasia: A distinctive fibroblastic pseudotumour occurring in debilitated patients. Am J Surg Pathol 1992;16:708-15. https://doi.org/10.1097/00000478-199207000-00009

14. Perosio P, Weiss S. Ischemic fasciitis: A juxta-skeletal fibroblastic proliferation with a predilection for elderly patients. Mod Pathol 1993;6:69-72.
15. Liegl B, Fletcher CD. Ischemic fasciitis: Analysis of 44 cases indicating an inconsistent association with immobility or debilitation. Am J of Surg Pathol 2008;32:1546-52. https://doi.org/10.1097/ PAS.0b013e31816be8db

16. Nucci MR, Granter SR, Fletcher CD. Cellular angiofibroma: A benign neoplasm distinct from angiomyofibroblastoma and spindle cell lipoma. Am J Surg Pathol 1997;21:636-44. https://doi.org/10.1097/00000478-199706000-00002

17. Laskin WB, Fetsch JF, Mostofi FK. Angiomyofibroblastomalike tumour of the male genital tract: Analysis of 11 cases with comparison to female angiomyofibroblastoma and spindle cell lipoma. Am J of Surg Pathol 1998;22:6-16. https://doi.org/10.1097/00000478-199801000-00002

18. McMenamin ME, Fletcher CD. Mammary-type myofibroblastoma of soft tissue: A tumour closely related to spindle cell lipoma. Am I Surg Pathol 2001;25:1022-9. https://doi.org/10.1097/00000478200108000-00006

19. Kurt H, Arnold CA, Payne JE, et al. Massive localized lymphedema: A clinicopathological study of 46 patients with an enrichment for multiplicity. Mod Pathol 2016;29:75-82. https://doi.org/10.1038/ modpathol.2015.135

20. Iwasa $Y$, Fletcher $C D$. Distinctive prepubertal vulval fibroma: $A$ hitherto unrecognized mesenchymal tumour of prepubertal girls: Analysis of 11 cases. Am J Surg Pathol 2004;28:1601-8. https://doi.org/10.1097/00000478-200412000-00008

21. Vargas SO, Kozakewich HP, Boyd TK, et al. Childhood asymmetric labium majus enlargement: Mimicking a neoplasm. Am J Surg Pathol 2005:29:1007-16.

22. Köhler P, Utermann $S$, Kahle B, et al. [Biker's nodule—perineal nodular induration of the cyclist]. Hautarzt 2000;51:763-5. https://doi.org/10.1007/s001050051211

23. Bauer $\mathrm{P}$, Etienney I. Affections périnéales liées au sport. 2008. Available at: http://www.em-consulte. com/en/article/99380. Accessed April 13, 2017.

Correspondence: Dr. Mohannad A. Awad, Department of Urology, University of California-San Francisco, San Francisco, CA, United States; mohannad.awad@ucsf.edu 